METHODS OF ANALYSIS BY THE U.S. GEOLOGICAL SURVEY NATIONAL WATER QUALITY LABORATORY-

DETERMINATION OF MOLYBDENUM IN WATER BY GRAPHITE FURNACE ATOMIC ABSORPTION SPECTROPHOTOMETRY

U.S. GEOLOGICAL SURVEY

Open-File Report 97-198

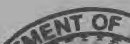


METHODS OF ANALYSIS BY THE U.S. GEOLOGICAL SURVEY

NATIONAL WATER QUALITY LABORATORY-

DETERMINATION OF MOLYBDENUM IN WATER BY GRAPHI $]$ 'E FURNACE ATOMIC ABSORPTION SPECTROPHOTOMETRY

By Sandra R. Jones and Betty J. McLain

U.S. GEOLOGICAL SURVEY

Open-File Report 97-198

Denver, Colorado 


\section{U.S. DEPARTMENT OF THE INTERIOR}

BRUCE BABBITT, Secretary

U.S. GEOLOGICAL SURVEY

Gordon P. Eaton, Director

The use of firm, trade, and brand names in this report is for identification purposes only and does not constitute endorsement by the U.S. Government.

For additional information write to:

Copies of this report can be purchased from:

U.S. Geological Survey

Chief, National Water Quality Laboratory

Box 25046, Mail Stop 407

Federal Center

Denver, CO 80225-0425
U.S. Geological Survey

Branch of Information Service:

Box 25286, Federal Center

Denver, CO 80225-0286 


\section{CONTENTS}

ABSTRACT

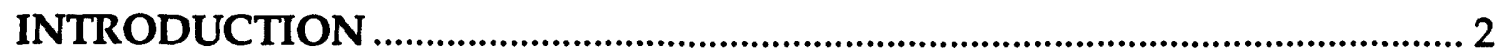

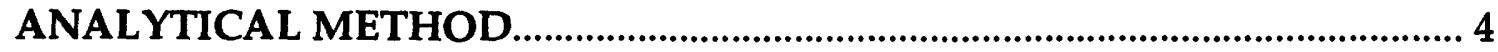

1. Application......................................................................................... 4

2. Summary of method.............................................................................. 4

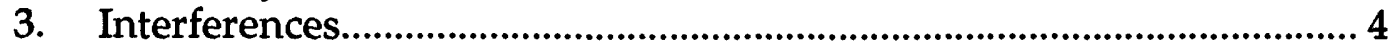

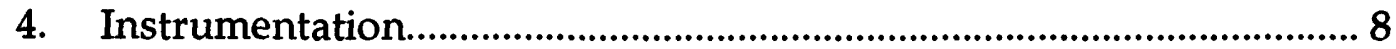

5. Apparatus …...................................................................................... 13

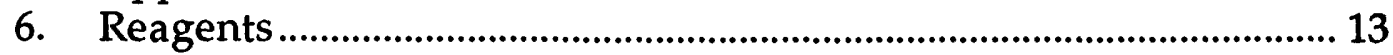

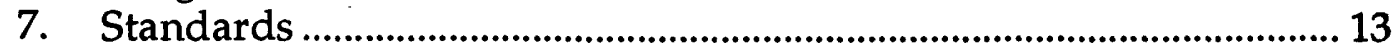

8. Sample preparation................................................................................. 14

9. Instrument performance................................................................... 14

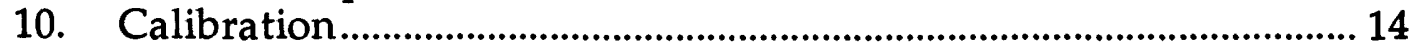

11. Procedure and data evaluation...................................................... 14

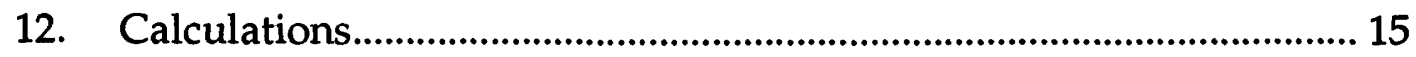

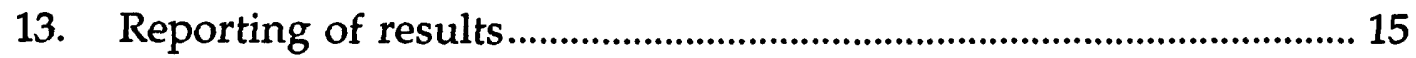

14. Precision and accuracy ............................................................................ 15

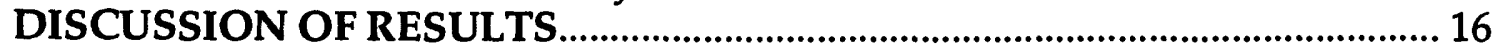

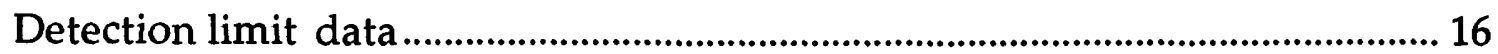

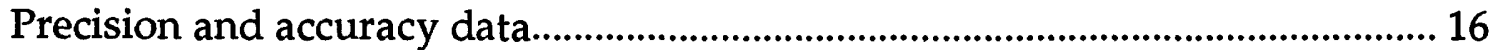

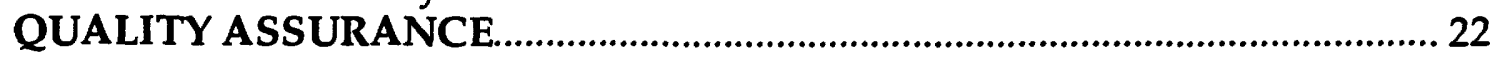

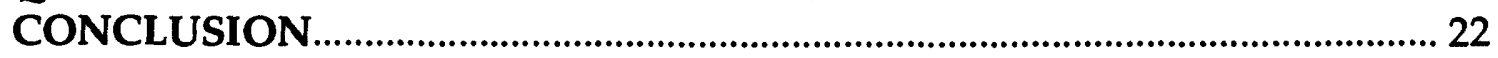

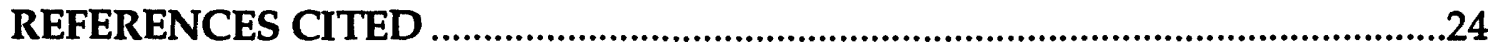

\section{ILLUSTRATIONS}

Figures 1-10. Graphs showing:

1. Spike recoveries of molybdenum with and without matrix modifier.

2. Spike recoveries of molybdenum using matrix modifier on various sample matrices

3. Results from three consecutive blank analyses following analysis of a sample containing 50 micrograms per liter of molybdenum

4. Results from blank analysis following analysis of a sample containing 25 micrograms per liter of molybdenum.................10

5. Results from blank analysis following analysis of a sample containing 8 to 13 micrograms per liter of molybdenum........11

6. Analytical results for molybdenum by the heated graphite atomizer relative to the transverse heated graphite atomizer 


\section{CONTENTS--Continued}

Pace

7. Precision and accuracy results for molybdenum determination by flame and graphite furnace atomic absorption spectrophotometry relative to Standard Reference Water Samples

8. Results for the determination of dissolved molybdenum in filtered water samples analyzed by graphite furnace atomic absorption spectrophotometry relative to flame atomic absorption spectrophotometry

9. Results for the determination of whole water recoverable molybdenum in nonfiltered water samples analyzed by graphite furnace atomic absorption spectrophotometry relative to flame atomic absorption spectrophotometry.

10. Results for the determination of dissolved molybdenum in filtered water samples analyzed by graphite furnace atomic absorption spectrophotometry relative to inductively coupled plasma-mass spectrometry

\section{TABLES}

Table 1. Sulfate interferences with and without matrix modifier .5

2. Memory effects following analysis of samples containing molybdenum concentrations of 50,25 , and 8 to 13 micrograms per liter

3. Graphite furnace precision for determining detection limits .........16

4. Precision of graphite furnace for determining molybdenum in a variety of samples

5. Precision and accuracy results for quality-control samples relative to established means and deviations

6. Precision and accuracy results for whole water recoverable Standard Reference Water Samples relative to their theoretical means and deviations 
CONVERSION FACTORS, ABBREVIATED WATER-QUALITY UNITS, Al 'D ADDITIONAL ABBREVIATIONS

\section{Multiply}

gram (g)

liter (L)

microgram $(\mu \mathrm{g})$

microliter $(\mu \mathrm{L})$

milliliter (mL)

nanometer $(\mathrm{nm})$

picogram (pg)
By

$3.53 \times 10^{-2}$

$3.38 \times 10^{1}$

$3.53 \times 10^{-8}$

$3.38 \times 10^{-5}$

$3.38 \times 10^{-2}$

$3.94 \times 10^{-8}$

$3.53 \times 10^{-14}$
To obtain

ounce, avoirdubois

ounce, fluid

ounce, avoirdupois

ounce, fluid

ounce, fluid

inch

ounce, avoirdupois

Degree Celsius $\left({ }^{\circ} \mathrm{C}\right)$ may be converted to degree Fahrenheit $\left({ }^{\circ} \mathrm{F}\right)$ by using the following equation:

$$
\mathrm{oF}=9 / 5\left({ }^{\circ} \mathrm{C}\right)+32
$$

Abbreviated water-quality units used in this report:

g/L gram per liter

$\mathrm{mg} / \mathrm{L} \quad$ milligram per liter

$\mu \mathrm{g} / \mathrm{L} \quad$ microgram per liter

$\mu \mathrm{S} / \mathrm{cm} \quad$ microsiemens per centimeter at 25 degrees Celsius

Other abbreviations used in this report:

a-s absorbance-seconds

ASTM American Society for Testing and Materials

F-AAS flame atomic absorption spectrophotometry

FEP fluorinated ethylene propylene

GF-AAS graphite furnace atomic absorption spectrophotometry

HGA heated graphite atomizer

ICP-AES inductively coupled plasma-atomic emission spectrometry

ICP-MS inductively coupled plasma-mass spectrometry

MDL method detection limit

MIBK methyl isobutyl ketone

Mo molybdenum

$\mathrm{M}_{\mathrm{O}} \quad$ characteristic mass

MRL method reporting limit

NWQL National Water Quality Laboratory

sp gr specific gravity

SRWS Standard Reference Water Samples

TDL theoretical detection limit 


\section{CONVERSION FACTORS, ABBREVIATED WATER-QUALITY UNITS, A ND ADDITIONAL ABBREVIATIONS--Continued}

THGA transverse heated graphite atomizer

USGS U.S. Geological Survey

$\mathrm{w} / \mathrm{v} \quad$ weight per volume

WWR whole water recoverable 


\title{
METHODS OF ANALYSIS BY THE U.S. GEOLOGICAL SURVEY NATIONAL WATER QUALITY LABORATORY-DETERMINATION OF MOLYBDENUM" IN WATER BY GRAPHITE FURNACE ATOMIC ABSORPTION SPECTROPHOTOMETRY
}

\author{
By Sandra R. Jones and Betty J. McLain
}

\begin{abstract}
Graphite furnace atomic absorption spectrophotometry (GF-AAS) is a sensitive, precise, and accurate method that can be used to determine molybdenum in water samples. This method has been developed to replace the chelationextraction method by flame atomic absorption spectrophotometry (F-AAS), reducing sample preparation time and safety hazards. The reporting range is 1 to 50 micrograms per liter $(\mu \mathrm{g} / \mathrm{L})$, with a method detection limit of $0.9 \mu \mathrm{g} / \mathrm{L}$ and a linear working limit of $50 \mu \mathrm{g} / \mathrm{L}$.

Although sulfate interferes in the determination of molybdenum, the use of magnesium nitrate in conjunction with ammonium phosphate as a matrix modifier minimizes this interference. Numerous water samples containing various concentrations of sulfate were spiked with $25 \mu \mathrm{g} / \mathrm{L}$ molybdenum and analyzed for a mean spike recovery of 91 percent.

Molybdenum tends to form carbides, resulting in memory-effect (carry-cver) interferences. Carry-over interferences of approximately $2 \mu \mathrm{g} / \mathrm{L}$ may result following a molybdenum concentration of $50 \mu \mathrm{g} / \mathrm{L}$. These carry-over interferences are eliminated by routine intermittent blank-sample analysis, a multistep hightemperature cleanout program, and the use of pyrolytically coated graphite tubes.

Precision and accuracy studies demonstrate that the GF-AAS method is comparatively accurate and more precise than the F-AAS method. Eleven standards tested with concentrations from 0.6 to $50 \mu \mathrm{g} / \mathrm{L}$ display a median relative standard deviation of 6.6 percent. Fourteen reference samples were tested to demonstrate precision and accuracy of the GF-AAS method; three of the reference samples show an improvement in precision when compared with the F-AAS method. Statistical comparison studies of dissolved and whole water recoveral-le analysis results on water samples demonstrated an insignificant difference betrieen the GF-AAS and F-AAS methods. The $p$-values indicated the differences between methods to be statistically different from zero; however, in both cases, the median differences are less than the method reporting limit of $1.0 \mu \mathrm{g} / \mathrm{L}$. Precision and accuracy by the graphite furnace method are further defined when compared $w^{\text {rith }}$ inductively coupled plasma-mass spectrometry. Using samples with low concentrations $(0-3.0 \mu \mathrm{g} / \mathrm{L})$, the paired $t$-test demonstrates the differences between methods to be statistically different from zero; however, the median difference is well below the method reporting limit.
\end{abstract}




\section{INTRODUCTION}

Molybdenum (Mo) is an accessory element in many metal ores. Soluble molybdates may appear in detectable concentrations in surface water, sedim ont, ground water, and vegetation at considerable distances from their source. Molybdenum occurs in oxidation states ranging from $\mathrm{Mo}^{+3}$ to $\mathrm{Mo}^{+6}$, but $\mathrm{t}$. e most common solid and aqueous phases contain $\mathrm{Mo}^{+4}$ and $\mathrm{Mo}^{+6}$. It is used extensively as an alloy in steel production, welding rods, an additive to lubricants, and in ceramics. Molybdenum is generally present in fossil fuels and can be spread through the environment by burning these materials. Molybdenum is also an essential trace element in animal and plant nutrition, especially for legumer. Major sources of contamination include waste from molybdenum mines and oretreatment facilities. Generally, lakes and rivers from areas not extensively $a$ ffected by contamination have less than $1 \mu \mathrm{g} / \mathrm{L}$ of molybdenum while streams afferted by molybdenum mining might have concentrations as great as $3,800 \mu \mathrm{g} / \mathrm{L}(\mathrm{Hem}, 1989$, p. 140).

The U.S. Geological Survey's National Water Quality Laboratory (NWQL) currently (1997) uses two methods for the determination of molybdenum ir water samples, inductively coupled plasma-atomic emission spectrometry (ICP-f ES) and inductively coupled plasma-mass spectrometry (ICP-MS). The F-AAS method discontinued in November 1994 had a method reporting limit (MRL) of $1 \mu \mathrm{g} / \mathrm{L}$ with an analytical range to $50 \mu \mathrm{g} / \mathrm{L}$. The ICP-AES method has a MRL of $10 \mu \mathrm{g} / \mathrm{L}$ with an analytical range to $10,000 \mu \mathrm{g} / \mathrm{L}$, and the ICP-MS method offers a MRL of $1.0 \mu \mathrm{g} / \mathrm{L}$ and an analytical range up to $100 \mu \mathrm{g} / \mathrm{L}$, but this method is limited to samples with specific conductances of $2,000 \mu \mathrm{S} / \mathrm{cm}$ or less. The GF-AAS method was developed to replace the F-AAS method for the determination of molybdenum because it offers excellent sensitivity and precision at low concentrations, has a comparable range, and is relatively interference free.

The F-AAS method required lengthy sample preparation and the use of reactive and hazardous reagents, such as methyl isobutyl ketone (MIBK) and 8-hydroxyquinoline, two organic materials that present health, safety, and hazardous waste problems. The chelation extraction procedure required approximately 8 hours to analyze a set of 50 samples, with the first 4 hours for sample preparation and the last 4 hours for sample analysis and hazardous waste disposal. The GF-AAS method requires neither sample preparation nor organic materials; however, the analytical principle is the same as F-AAS. Ground state atoms are heated and introduced into the optical path of an elemental light source. The atoms absorb the light of the wavelength at the resonant frequency, and an absorbance signal is produced that is directly proportional to the concentration of molybdenum in the sample. Instead of introducing a sample into a flame through nebulization, a small aliquot of sample is introduced inside the graphite tub? where the tube is heated to excite the atoms using a specified temperature.

Molybdenum determination by GF-AAS requires five basic steps: drying, pyrolysis, atomization, clean out, and cool down. The sample and a matrix modifier are pipeted inside the tube. The graphite tube is purged with a continuous flow of argon gas, and, through the use of a controlled temperature program, is gently 
heated (no boiling) to dryness. Following the dry step, the temperature is raised to a pyrolysis or char temperature, and with the aid of a matrix modifier the interference effects caused by concomitant matrix components are minimized. After pyrolysis, the tube may be cooled (instrument specific) to allow for uniform heating follow'ed by rapid ( $<1$ second) heating to an atomization temperature. Gas flow stops and the sample is atomized in the path of the molybdenum light source where absorptic $n$ is measured on the resulting atomic cloud. Following atomization, the gas flow resumes, and high-temperature clean-out and cool-down steps provide a clean environment in preparation for the next sample. An example of a molybdenum furnace program might be as follows:

\begin{tabular}{lccc}
\multicolumn{1}{c}{ Step } & Temperature $\left(^{\circ} \mathrm{C}\right)$ & Ramp & Hold \\
\hline Dry & 100 & 1 & 40 \\
Pyrolysis & 1,650 & 5 & 20 \\
Cool down & 20 & 1 & 15 \\
Atomization & 2,650 & 0 & 8 \\
Clean out* & 2,700 & 1 & 3 \\
Cool down & 20 & 1 & 10 \\
Clean out & 2,700 & 1 & 4 \\
Cool down & 20 & 1 & 10 \\
Clean out & 2,700 & 1 & 3 \\
Cool down & 20 & 1 & 10
\end{tabular}

*The molybdenum program may repeat these steps to maximize removal of matrix components.

GF-AAS is widely used and accepted and has proven to be an efficient and effective tool for the determination of many trace elements including molybderum. The low detection limit, small sample size, analytical range, and minimal sample preparation significantly expand the use compared with other analytical methods.

This report describes the method for determining trace concentrations of molybdenum developed by the U.S. Geological Survey (USGS) for use in the Survey's NWQL. This method, which was implemented in November 1994, supplements other methods of the USGS for determination of molybdenum in water that are described by Fishman and Friedman (1989) and by Fishman (1993). A detailed description of all aspects of this method follows from application and results to quality assurance. 


\title{
ANALYTICAL METHOD \\ Inorganic Constituents and Parameter Codes
}

\author{
Molybdenum, dissolved, I-1492-96 ( $\mu \mathrm{g} / \mathrm{L}$ as Mo): $01060 \mathrm{C}$ \\ Molybdenum, whole water recoverable, I-3492-96 ( $\mu \mathrm{g} / \mathrm{L}$ as Mo): 01062B
}

\section{Application}

1.1 This method is used to analyze filtered and nonfiltered water sa mples for dissolved and whole water recoverable (WWR) analysis. Using a $20-\mu \mathrm{L}$ sample and Zeeman background correction, the method is applicable in the range frcm 1 to $50 \mu \mathrm{g} / \mathrm{L}$. Sample solutions that contain molybdenum concentrations exceeding the upper limit of the analytical range must be diluted and reanalyzed or analyzet by an alternate method.

1.2 Furnace temperature programs, volumes, matrix modifiers, and other instrumental settings may be modified provided that characteristic mass $( \pm 20$ percent) is maintained, and the method detection limit (MDL) is met or improved. Characteristic mass $\left(\mathbf{M}_{\mathrm{O}}\right)$ best describes instrumental and operational perforn ance; it is defined as the mass of an analyte, in picograms, required to produce a signal of 0.0044 absorbance-seconds (a-s), so that instrument performance and optimization can be evaluated (Beaty, 1988, p. 5-1).

\section{Summary of method}

Molybdenum determination by GF-AAS requires placing a small volume of sample in a graphite tube, which is held between two graphite rings with quirtz windows at each end, producing a somewhat closed environment to enhanc? the absorbance signal. The tube is pyrolytically coated with high-density carbon to reduce the formation of nonvolatile carbides and prevent surface adsorption of the sample onto the wall of the graphite tube, resulting in longer tube life (Ghe and others, 1983, p. 711). The sample is evaporated to dryness, pyrolized, and atomized using specified temperatures and high-temperature ramping. The absorbancesecond signal is produced and compared to standards. Background noise is corrected using Zeeman-effect background correction, that is, a magnetic field is turned on and off at approximately 60 hertz (cycles per second) during atomization, causing the sample signal to split into polarized and nonpolarized components that correct for background interference.

\section{Interferences}

3.1 "Sulfate interferes with the GF-AAS determination of molybdenum in aqueous solutions with concentrations of only 0.5 percent weight per volume $(w / v)$ sodium sulfate $\left(\mathrm{Na}_{2} \mathrm{SO}_{4}\right)$, causing complete elimination of the molybdenum absorbance peak in solutions free of other salts" (Emerick, 1987, p. 69). To reduce the sulfate interference, a matrix modifier is used to facilitate the determination of molybdenum in the presence of solutions containing sulfate. The use of 
magnesium nitrate in conjunction with ammonium phosphate as a matrix modifier reduces the sulfate interference considerably. Nine water samples containing elevated sulfate concentrations with specific conductances of 3,000 to $6,000 \mu \mathrm{S} / \mathrm{cm}$ and sulfate concentrations of 895 to 3,245 mg/L were analyzed and spiked with $25 \mu \mathrm{g} / \mathrm{L}$ of molybdenum. Without modifier, the mean spike recovery equaled 37 percent, whereas with modifier, the spike recovery rose to 83 percent. Of these samples, 78 percent fell within \pm 20 of 100 percent; all sample recoveries fell below 60 percent without the use of matrix modifier, as shown in figure 1. A mean spike recovery of 91 percent, using a matrix modifier on water samples with various ranges of sulfate concentrations and specific conductances ranging from 2.0 to 7,800 $\mu \mathrm{S} / \mathrm{cm}$, is shown in figure 2. All samples fell within \pm 20 of 100 percent except for two, which had specific conductances greater than $5,000 \mu \mathrm{S} / \mathrm{cm}$ and sulfate greater than $3,000 \mathrm{mg} / \mathrm{L}$. To rule out matrix interferences, all samples with specific conductances greater than or equal to $5,000 \mu \mathrm{S} / \mathrm{cm}$ should be diluted or spiked. or both.

Studies were performed using sodium sulfate to determine at what concentration sulfate might interfere. Solutions containing $0,0.1,0.5$, and 1.0 percent sodium sulfate were spiked with $25 \mu \mathrm{g} / \mathrm{L}$ molybdenum and analyzed with and without matrix modifier. See table 1. As expected, without matrix modifier, there is nearly complete elimination of molybdenum at a 0.5 -percent concentration of sodium sulfate, whereas with matrix modifier, recovery increased to 70 percent.

Table 1. --Sulfate interferences with and without matrix modifier

$[\%$, percent; $\mathrm{mg} / \mathrm{L}$, milligrams per liter]

\begin{tabular}{cccc}
\hline $\begin{array}{c}\text { Sodium sulfate } \\
(\%)\end{array}$ & $\begin{array}{c}\text { Sulfate } \\
(\mathrm{mg} / \mathrm{L})\end{array}$ & $\begin{array}{c}\text { Spike recovery } \\
\text { with modifier }(\%)\end{array}$ & $\begin{array}{c}\text { Spike recovery } \\
\text { without modifer }(\%)\end{array}$ \\
\hline 0 & 0 & 94 & 94 \\
0.1 & 676 & 71 & 16 \\
0.5 & 3,380 & 70 & 5 \\
1.0 & 6,760 & 30 & 0 \\
\hline
\end{tabular}

3.2 Carbide may form in the furnace environment because molybdenum binds with carbon to form $\mathrm{MoC}$, resulting in some signal loss. "During the dring step, $\mathrm{MoO}_{3}$ is formed; it melts at $1,340^{\circ} \mathrm{C}$ and is further converted by carbon to $\mathrm{Mo}_{2} \mathrm{C}$ with pyrolysis temperatures up to $2,150^{\circ} \mathrm{C}$. Above $2,250^{\circ} \mathrm{C}$, the $\mathrm{Mo}_{2} \mathrm{C}$ is converted to $\mathrm{MoC}$ and Mo. The absorbance signal is larger if ashing [pyrolysis] does not exceed $2,100^{\circ} \mathrm{C}$. This minimizes the formation of $\mathrm{MoC}$, some of which remains after the atomization step" (Slavin, 1984, p. 123), causing memory effects. The use of pyrolytically coated tubes helps to reduce the formation of carbides. The high temperature (approximately $2,700^{\circ} \mathrm{C}$ ) for cleanout is necessary to remove the $\mathrm{MoC}$ found on the wall of the graphite tube, but it reduces tube life considerably. To decrease memory effects and increase tube life, multiple, short, high-temperat-re 


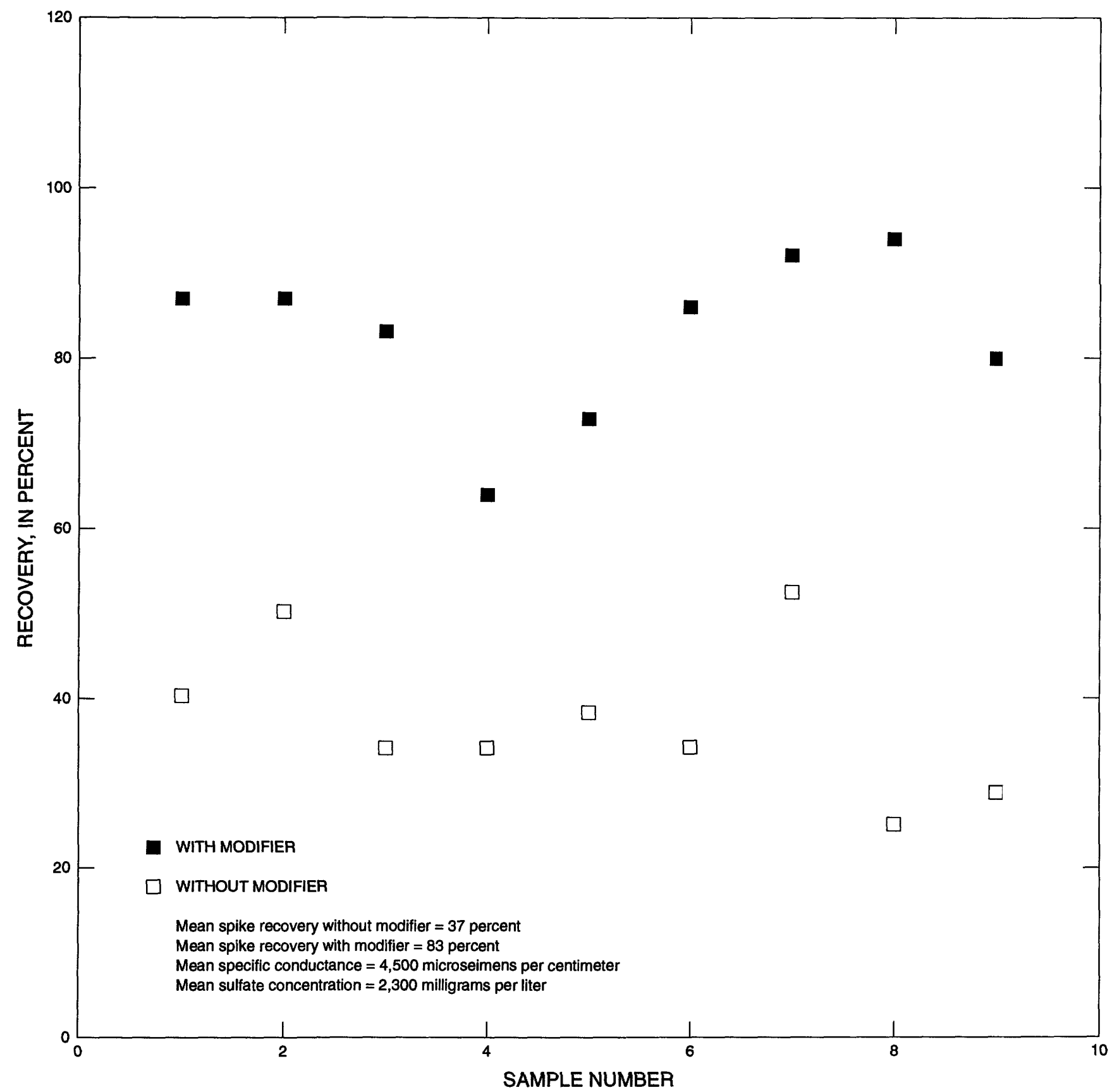

Figure 1.--Spike recoveries of molybdenum with and without matrix modifier. 


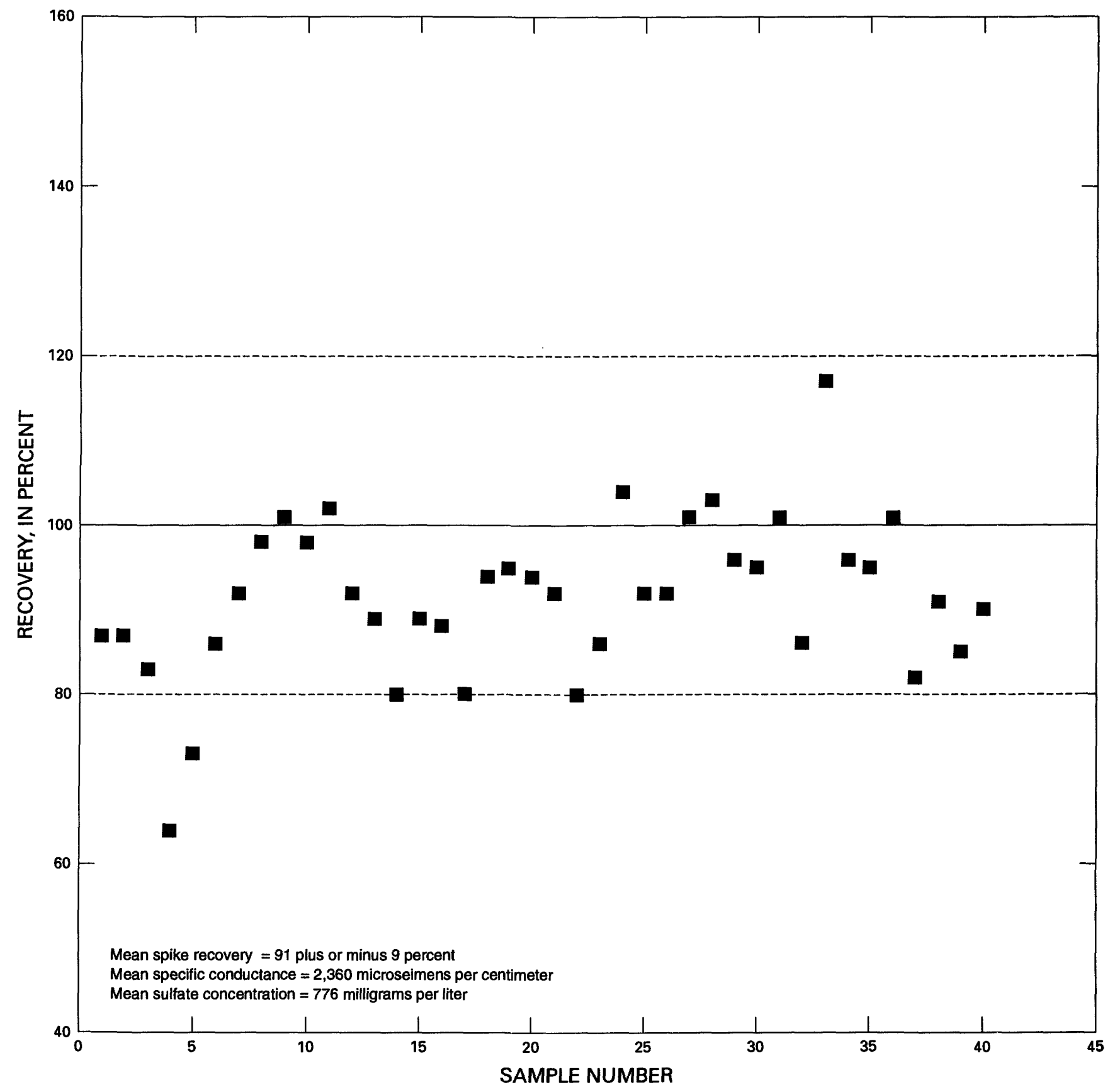

Figure 2.--Spike recoveries of molybdenum using matrix modifier on various sample matrices. 
clean-out steps are suggested rather than one long clean-out step. Studies were performed to determine memory effects for current furnace programs using three high-temperature clean-out steps. Results of memory effects obtained by the analysis of blank samples following various concentrations of molybdenum are listed in table 2 and shown in figures 3 through 5 . Memory effects are evident at the 25- and $50-\mu \mathrm{g} / \mathrm{L}$ concentrations. Therefore, any analysis immediately following a sample analyzed with a molybdenum concentration of about $25 \mu \mathrm{g} / \mathrm{L}$ and greater will be affected by carryover and must be reanalyzed. One to two blanks analyzed between each sample is recommended to reduce the need to reanalyze samples because of memory effects, and, at the same time, verify baseline return between each sample analysis.

Table 2.--Memory effects following analysis of samples containing molybdenum concentrations of 50, 25, and 8 to 13 inicrograins per liter

[ $\mu \mathrm{g} / \mathrm{L} ;$ micrograms per liter; $\mathrm{n}$, number of determinations; NA, not analyzed]

\begin{tabular}{|c|c|c|c|c|c|c|c|c|c|}
\hline \multirow[t]{2}{*}{$\begin{array}{l}\text { Concen- } \\
\text { tration } \\
(\mu g / L)\end{array}$} & \multicolumn{3}{|c|}{$\begin{array}{r}\text { Blank } 1 \\
(\mu \mathrm{g} / \mathrm{L}) \\
\end{array}$} & \multicolumn{3}{|c|}{$\begin{array}{c}\text { Blank } 2 \\
(\mu \mathrm{g} / \mathrm{L})\end{array}$} & \multicolumn{3}{|c|}{$\begin{array}{c}\text { Blank } 3 \\
(\mu \mathrm{g} / \mathrm{L})\end{array}$} \\
\hline & Mean & $\begin{array}{r}\text { Standard } \\
\text { deviation }\end{array}$ & $n$ & Mean & $\begin{array}{l}\text { Standard } \\
\text { deviation }\end{array}$ & $n$ & Mean & $\begin{array}{l}\text { Standard } \\
\text { deviation }\end{array}$ & $n$ \\
\hline 50 & 2.4 & 0.9 & 39 & 1.0 & 0.5 & 38 & 0.5 & 0.3 & 21 \\
\hline 25 & 1.0 & 0.7 & 41 & NA & NA & NA & NA & NA & NA \\
\hline $8-13$ & 0.4 & 0.5 & 38 & NA & NA & NA & NA & NA & NA \\
\hline
\end{tabular}

\section{Instrumentation}

4.1 The atomic absorption spectrophotometer graphite furnace must be equipped with Zeeman-background correction, digital integrator to quantitate peak areas, programmable temperature control for high-temperature ramping, an autosampler, and controlled gas flow. The graphite furnace must be capable of reaching a temperature sufficient to atomize molybdenum. At present (1997), two types of graphite furnace are acceptable for use - the heated graphite atomizer (HGA) and the transverse heated graphite atomizer (THGA). These two types of furnace designs were compared by analyzing samples at various concentrations. Since the sample data were neither symmetric nor normally distributed, a sign test (Ott, 1993, p. 297-301) was used to measure if results from the THGA were significantly different from the HGA. The sign test on the median of the differences for 104 samples analyzed by each method yielded a $p$-value equal to 0.69 , indicating that no significant difference exists between the instruments (see fig. 6).

4.2 Refer to Beaty (1988) and Beaty and Kerber (1993) for instrumental performance. 


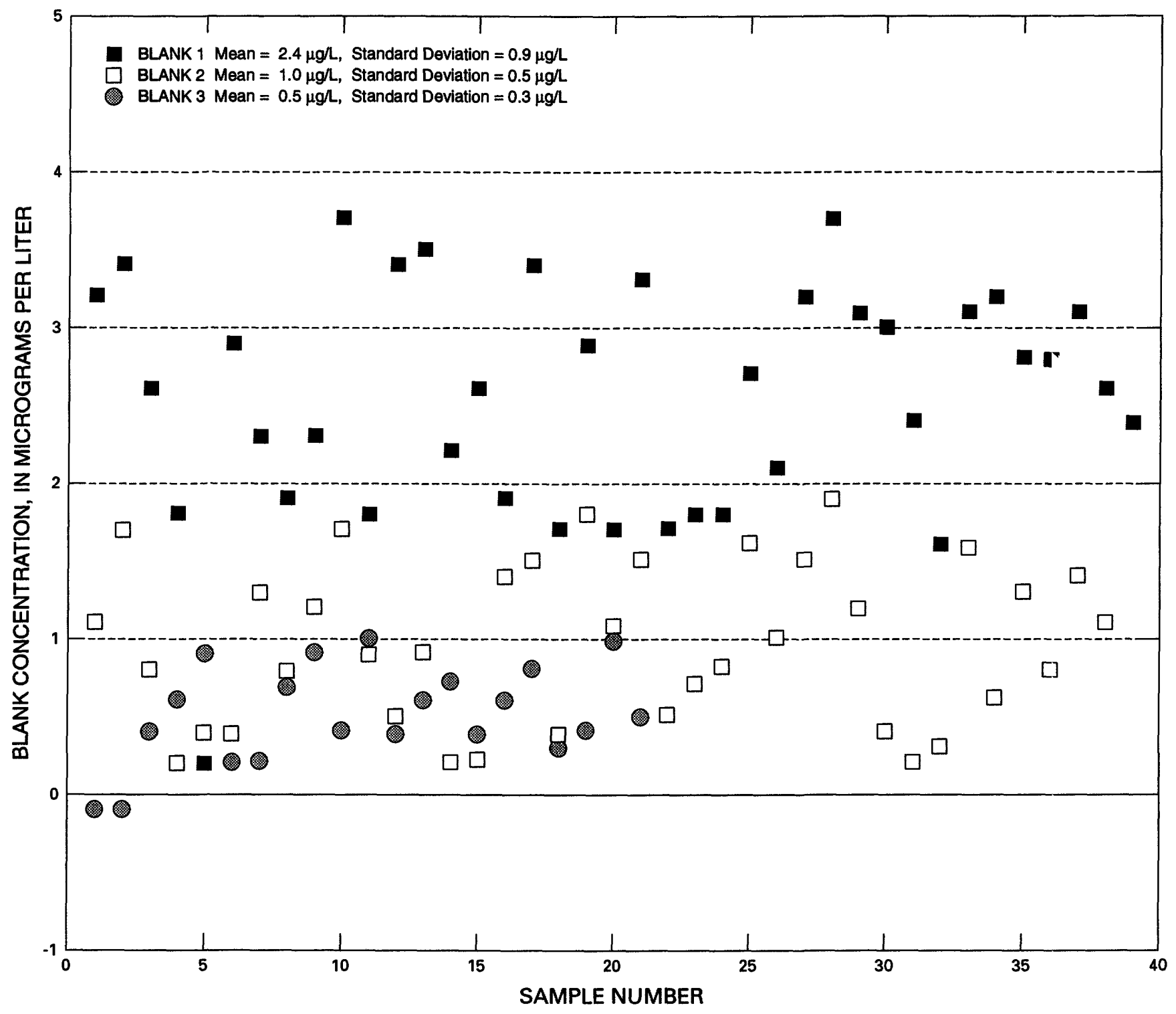

Figure 3.--Results from three consecutive blank analyses following analysis of a sample containing 50 micrograms per liter $(\mu \mathrm{g} / \mathrm{L})$ of molybdenum. 


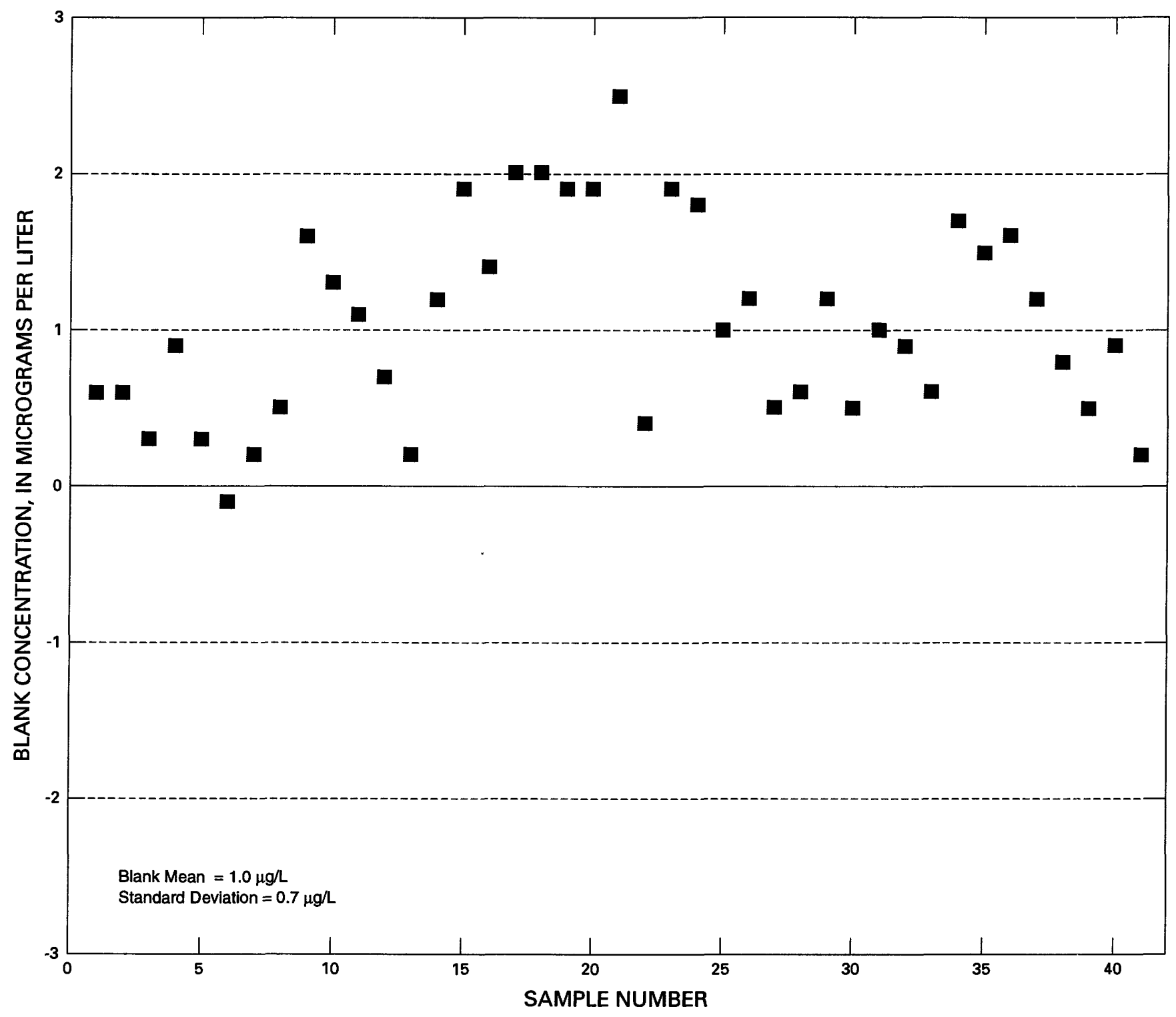

Figure 4.--Results from blank analysis following analysis of a sample containing 25 micrograms per liter $(\mu \mathrm{g} / \mathrm{L})$ of molybdenum. 


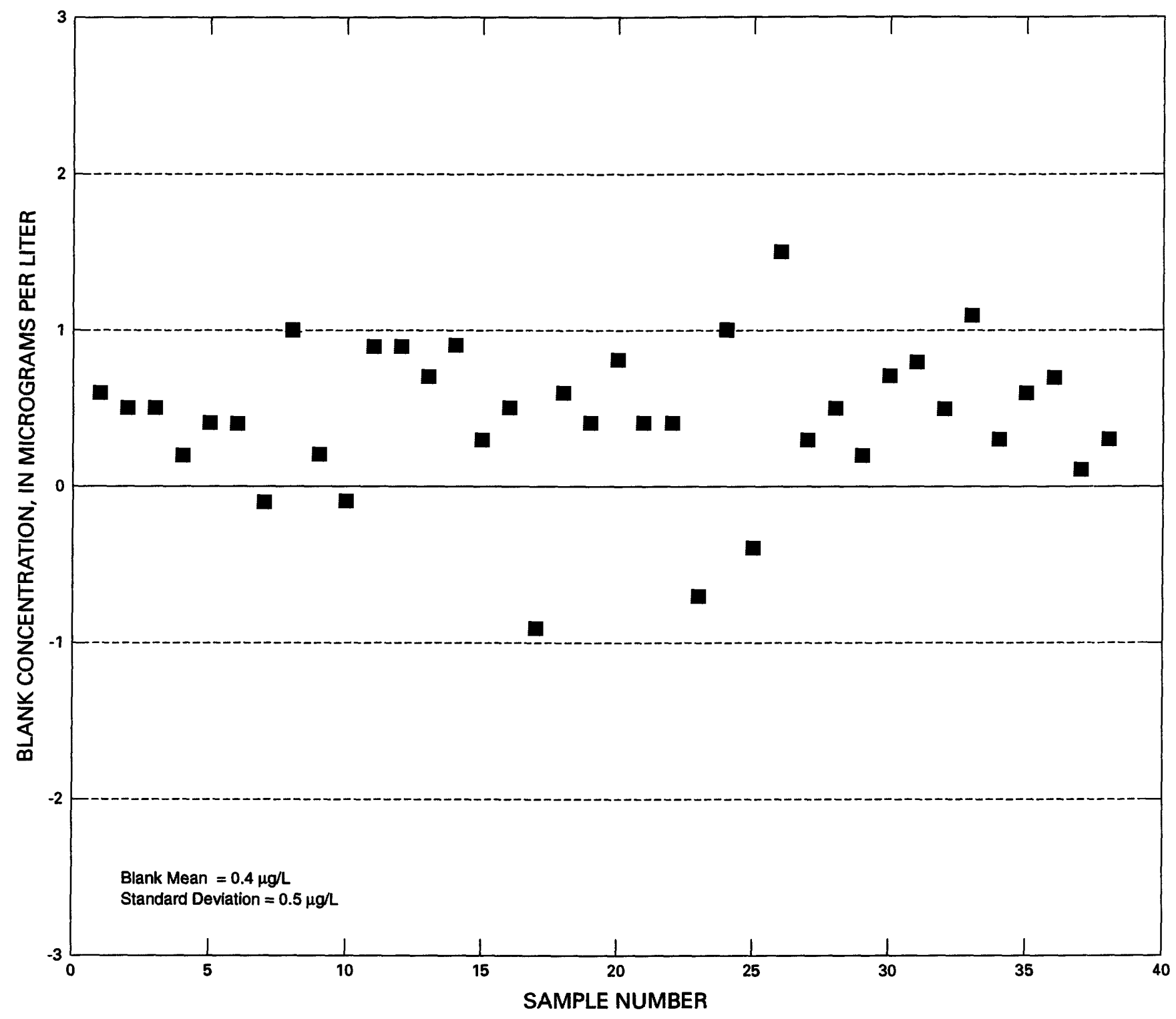

Figure 5.--Results from blank analysis following analysis of a sample containing 8 to 13 micrograms per liter $(\mu \mathrm{g} / \mathrm{L})$ of molybdenum. 


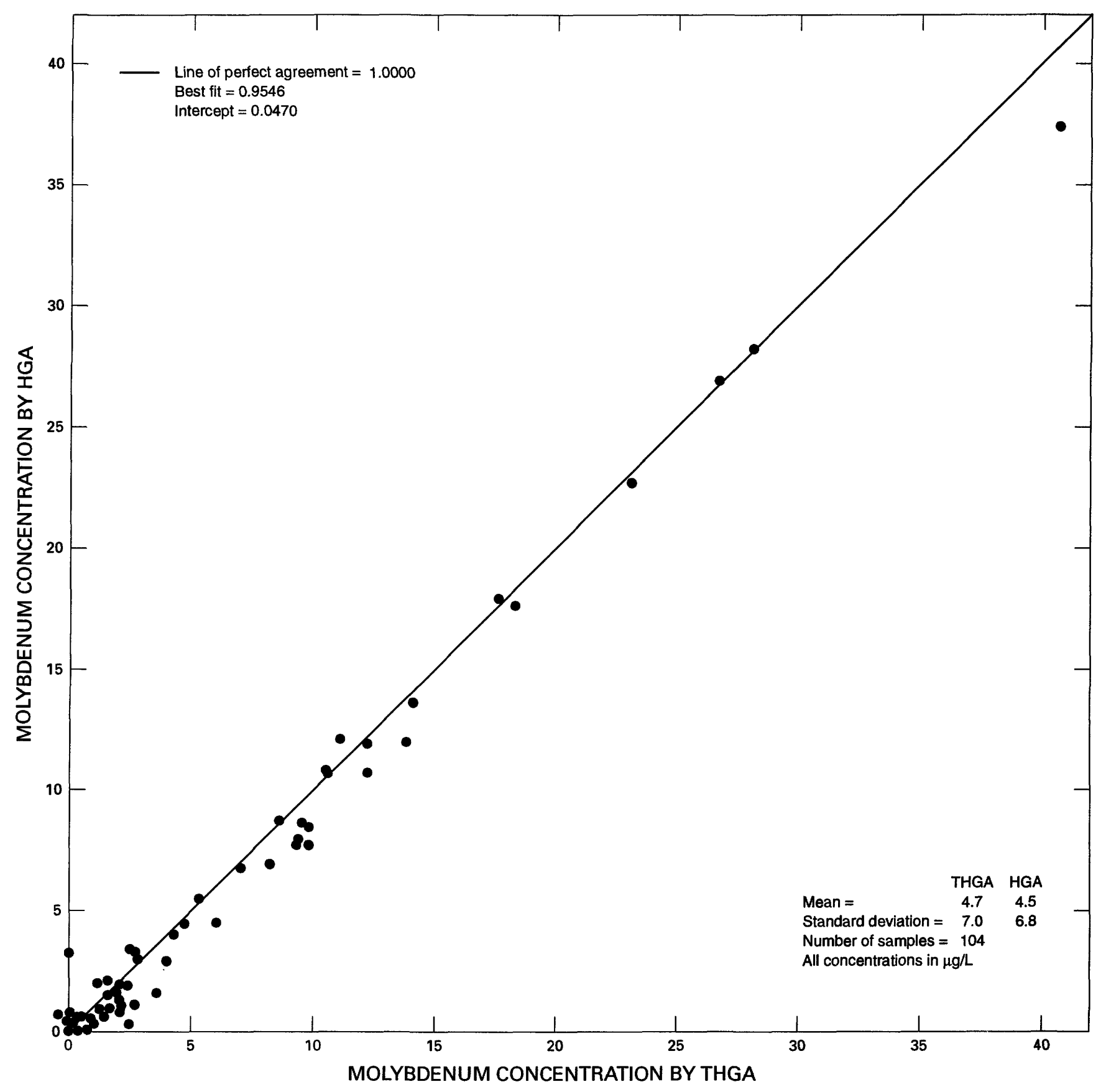

Figure 6.--Analytical results for molybdenum by the heated graphite atomizer (HGA) relative to the transverse heated graphite atomizer (THGA). 


\section{Apparatus}

5.1 Graphite furnace atomic absorption spectrophotometer. See section 4, Instrumentation.

5.2 Graphite tubes. Pyrolytically coated graphite tubes without platform for HGA use and THGA designed tubes (with platform) for THGA use.

5.3 Labware. Many trace metals with low concentrations adsorb rapidly to glassware. To preclude this problem, use fluorinated ethylene propylene (FEP) or Teflon labware.

5.4 Argon. Standard, welder's grade, commercially available.

5.5 Molybdenum hollow cathode lamp. Designed for a wavelength setting of $313.3 \mathrm{~nm}$.

\section{Reagents}

6.1 Matrix modifier solution, $13.8 \mathrm{~g} / \mathrm{L}$ ultrapure ammonium phosphate $\left(\mathrm{NH}_{4} \mathrm{H}_{2} \mathrm{PO}_{4}\right)$ and $2.0 \mathrm{~g} / \mathrm{L}$ ultrapure magnesium nitrate $\left[\mathrm{Mg}\left(\mathrm{NO}_{3}\right)_{2} \cdot 6 \mathrm{H}_{2} \mathrm{O}\right]$ added to approximately $950 \mathrm{~mL}$ water; mix and dilute to $1,000 \mathrm{~mL}$.

6.2 Nitric acid, concentrated, ultrapure (sp gr 1.41): J.T. Baker "Ultrex" brand $\mathrm{HNO}_{3}$ has been found to be adequately pure; however, check each lot for contamination.

6.3 Water: All references to water shall be understood to mean Type I reagent water (American Society for Testing and Materials, 1995, p. 122-124).

6.4 Nitric acid, 10 percent: In a 1-L volumetric flask containing approximately $500 \mathrm{~mL}$ of water, add $100 \mathrm{~mL}$ of concentrated $\mathrm{HNO}_{3}$ (sp gr 1.41), then fill to volume with water.

6.5 Water, acidified: Add $4.0 \mathrm{~mL}$ ultrapure concentrated $\mathrm{HNO}_{3}$ (sp gr 1..41) to each liter of water for a final concentration of 0.4 percent.

\section{Standards}

7.1 Molybdenum standard solution $I, 1.00 \mathrm{~mL}=1,000 \mu \mathrm{g}$ Mo: Use a commercially prepared and certified molybdenum calibration standard, 1,000 $\mathrm{mg} / \mathrm{L}$, 0.100 percent $\mathrm{w} / \mathrm{v}$.

7.2 Molybdenum standard solution $I I, 1.00 \mathrm{~mL}=100.0 \mu \mathrm{g}$ Mo: Dilute $10.0 \mathrm{~mL}$ molybdenum standard solution I to $100 \mathrm{~mL}$ (NOTE 1).

NOTE 1. Use acidified water to make all dilutions. Store all standards ir sealed Teflon or FEP containers. Standards stored for 6 months yielded concentrations equal to freshly prepared solutions.

7.3 Molybdenum standard solution III, $1.00 \mathrm{~mL}=1.00 \mu \mathrm{g}$ Mo: Dilute 10.0 $\mathrm{mL}$ of molybdenum standard solution II to $1,000 \mathrm{~mL}$.

7.4 Molybdenum working standard solution $I, 1.00 \mathrm{~mL}=0.010 \mu \mathrm{g} \mathrm{Mo:}$ Dilute $10.0 \mathrm{~mL}$ of molybdenum standard solution III to $1,000 \mathrm{~mL}$. 
7.5 Molybdenum working standard solution $I I, 1.00 \mathrm{~mL}=0.025 \mu \mathrm{g}$ Mo: Dilute $25.0 \mathrm{~mL}$ of molybdenum standard solution III to $1,000 \mathrm{~mL}$.

7.6 Molybdenum working standard solution III, $1.00 \mathrm{~mL}=0.050 \mu \mathrm{g}$ Mo: Dilute $50.0 \mathrm{~mL}$ of molybdenum standard solution III to $1,000 \mathrm{~mL}$.

\section{Sample preparation}

Upon receipt in the laboratory, filtered samples for dissolved analysis do not require sample preparation. Nonfiltered samples for WWR analysis require inbottle digestion before molybdenum can be determined (Hoffman and other:, 1996).

\section{Instrument performance}

9.1 Instrument performance (see section 1.2) is best demonstrated ty characteristic mass and method detection measurements. The calculation for determining characteristic mass is shown in section 12 .

9.2 The current (1997) instrument $\mathrm{M}_{\mathrm{o}}$ is $9.0 \mathrm{pg}$ for the HGA and $12.0 \mathrm{pg}$ for the THGA Perkin-Elmer ${ }^{\mathrm{TM}}$ furnaces; these characteristic mass measurements are subject to change with advanced technology.

\section{Calibration}

The calibration curve is constructed from working standards using a linear curve for a correlation coefficient of 0.999 or better. Generally, the curve is linear up to a peak height absorbance of 1.8 .

\section{Procedure and data evaluation}

11.1 Analyze samples in a clean analyte-free environment.

11.2 Rinse the sample cups at least twice with sample before filling. Place the cups in sample tray and cover. Adjust the autosampler so that only the injection tip contacts the sample.

11.3 Analyze blanks prior to sample analysis to condition the (new) graphite tube and to verify that acidified water and modifier are not contaminated. If contaminated (indicated by a peak formation), repour the blank or modifier, or both, to eliminate the problem. If the acidified water or the modifier, or both, are contaminated at their sources, remake the solutions using a new bottle or lot of acid or matrix modifier chemical if necessary. If contamination persists, troubleshoot by changing the graphite tube or cleaning the contact rings, or both.

11.4 In sequence, inject matrix modifier (see note 2) with each aliquot of blank and a minimum of three standards to construct the calibration curve from the absorbance-second measurements.

11.5 Similarly, analyze samples by injecting matrix modifier (see ncte 2) with each sample.

11.6 Analyze a quality-control sample immediately following calibration and after every tenth sample (minimum). Analyze a blank with each set of samples. 
NOTE 2: Currently (1997), $2 \mu \mathrm{L}$ of matrix modifier is used for each $20-\mu \mathrm{L}$ sample.

\section{Calculations}

\subsection{Characteristic Mass $\left(\mathrm{M}_{\mathrm{O}}\right)$}

$M_{0}(p g)=\frac{\text { Sample volume }(\mu \mathrm{L}) \times \text { analyte concentration }(\mu \mathrm{g} / \mathrm{L}) \times 0.0044 \text { absorbance }- \text { seconds }}{\text { Observed peak area, absorbance }- \text { seconds }}=$ Calculated $M_{0}$.

Acceptable ranges include an interval of 20 percent, calculated as follows:

$$
\text { Percent difference }=\frac{\text { Calculated } M_{o}-\text { Instrument } M_{0}}{\text { Instrument } M_{o}} \times(100)=\text { percent. }
$$

\subsection{Spikes}

$\frac{(\text { Sample }+ \text { Spike })-(\text { Sample })}{\text { (Theoretical spike concentration })} \times(100)=$ percent re covery .

\section{Reporting of results}

Report dissolved (01060C) and WWR (01062B) molybdenum concentrations as follows: Less than $1.0 \mu \mathrm{g} / \mathrm{L}$, as less than $1 \mu \mathrm{g} / \mathrm{L} ; 1.0$ to $100 \mu \mathrm{g} / \mathrm{L}$, to the nearest microgram per liter; $100 \mu \mathrm{g} / \mathrm{L}$ and greater, two significant figures.

\section{Precision and accuracy}

Precision and accuracy are determined by comparing quality-control samples and water samples between methods. Numerous studies were conducted to demonstrate GF-AAS performance. See the following discussion for results. 


\section{DISCUSSION OF RESULTS}

\section{Detection Limit Data}

The MDL is defined as the minimum concentration of a substance that can be measured and reported with 99-percent confidence that the analyte concentrition is greater than zero (Environmental Protection Agency, 1993, p. 569-570). The theoretical detection limit (TDL) was determined to be $0.9 \mu \mathrm{g} / \mathrm{L}$ for molybderum; it was based on three times the standard deviation of multiple blank determinations. The MDL is determined using a standard with a concentration between one and five times the TDL. A $1.0-\mu \mathrm{g} / \mathrm{L}$ molybdenum standard was used to determine the MDL of $0.9 \mu \mathrm{g} / \mathrm{L}$ for molybdenum. Data for determining the MDL are listed in table 3 .

Table 3.--Graphite furnace precision for determining detection limits

$[\mu \mathrm{g} / \mathrm{L}$, micrograms per liter; TDL, theoretical detection limit; MDL, method detection limit; NA, not analyzed]

\begin{tabular}{ccccccc}
\hline $\begin{array}{c}\text { Theoretical } \\
\text { concentration } \\
(\mu \mathrm{g} / \mathrm{L})\end{array}$ & $\begin{array}{c}\text { Mean } \\
\text { concentration } \\
(\mu \mathrm{g} / \mathrm{L})\end{array}$ & $\begin{array}{c}\text { Standard } \\
\text { deviation } \\
(\mu \mathrm{g} / \mathrm{L})\end{array}$ & $\begin{array}{c}\text { TDL } \\
(\mu \mathrm{g} / \mathrm{L})\end{array}$ & $t$ value & $\begin{array}{c}\text { Degrees of } \\
\text { freedom } \\
(\mathbf{n}-\mathbf{1})\end{array}$ & $\begin{array}{c}\text { MDL } \\
(\mu \mathrm{g} / \mathrm{L})\end{array}$ \\
\hline 0 & 0.09 & 0.31 & 0.9 & $\mathrm{NA}$ & 9 & NA \\
1.0 & 1.06 & 0.31 & n/a & 2.821 & 9 & 0.9 \\
\hline
\end{tabular}

\section{Precision and Accuracy Data}

Various studies using a variety of filtered and nonfiltered quality-control and water samples for dissolved and WWR analysis were performed to measure the precision and accuracy of the graphite furnace method for determining molybdenum.

Samples were analyzed over a period of 35 days to demonstrate acceptable precision (table 4). The mean relative standard deviation ranged from about 58 percent at $0.6 \mu \mathrm{g} / \mathrm{L}$ to 5 percent at $33 \mu \mathrm{g} / \mathrm{L}$; the median relative standard deviation was 6.6 percent for molybdenum concentrations ranging from 0.6 to $50.1 \mu \mathrm{g} / \mathrm{L}$.

The accuracy of molybdenum determinations by GF-AAS was verifiec' by analyzing USGS Standard Reference Water Samples (SRWS) and commerciclly prepared and certified standards (SPEX $\left.{ }^{\mathrm{TM}}\right)$. All results were well within the established norms for the means. Precision and accuracy results are listed in table 5. 
Table 4.--Precision of graphite furnace for determining molybdenum in a variety of samples

$[\mu \mathrm{g} / \mathrm{L}$, micrograms per liter $]$

\begin{tabular}{cccc}
$\begin{array}{c}\text { Mean } \\
(\mu \mathrm{g} / \mathrm{L})\end{array}$ & $\begin{array}{c}\text { Standard } \\
\text { deviation } \\
(\mu \mathrm{g} / \mathrm{L})\end{array}$ & $\begin{array}{c}\text { Number of } \\
\text { determinations }\end{array}$ & $\begin{array}{c}\text { Relative standard } \\
\text { deviation } \\
\text { (percent) }\end{array}$ \\
\hline 0.6 & 0.35 & 10 & 58 \\
1.2 & .20 & 10 & 16.6 \\
2.8 & .18 & 10 & 6.4 \\
3.7 & .43 & 10 & 11.6 \\
5.8 & .47 & 10 & 8.1 \\
13.3 & .79 & 10 & 5.9 \\
20.3 & 1.34 & 10 & 6.6 \\
32.9 & 1.66 & 9 & 5.0 \\
36.6 & 2.40 & 10 & 6.6 \\
40.8 & 2.50 & 10 & 6.1 \\
50.1 & 4.75 & 38 & 9.5 \\
\hline
\end{tabular}

Table 5.--Precision and accuracy results for quality-control samples relative to established moans and deviations

[NWQL, National Water Quality Laboratory; $\mu \mathrm{g} / \mathrm{L}$, micrograms per liter; n, number of determinations; SPEX, commercially prepared and certified standards; SFWS, U.S. Geological Survey Standard Reference Water Samples; --, not establish?d]

\begin{tabular}{|c|c|c|c|c|c|}
\hline \multirow[b]{2}{*}{$\begin{array}{l}\text { Reference } \\
\text { number }\end{array}$} & \multicolumn{2}{|c|}{$\begin{array}{l}\text { NWQL graphite } \\
\text { furnace concentration }\end{array}$} & \multirow[b]{2}{*}{$\mathbf{n}$} & \multicolumn{2}{|c|}{ Theoretical concentration } \\
\hline & $\begin{array}{l}\text { Mean } \\
(\mu \mathrm{g} / \mathrm{L})\end{array}$ & $\begin{array}{c}\text { Standard } \\
\text { deviation } \\
(\mu \mathrm{g} / \mathrm{L})\end{array}$ & & $\begin{array}{l}\text { Mean } \\
(\mu \mathrm{g} / \mathrm{L})\end{array}$ & $\begin{array}{c}\text { Standard } \\
\text { deviation } 1 \\
(\mu \mathrm{g} / \mathrm{L} .)\end{array}$ \\
\hline SPEX-20 & 20.8 & 2.4 & $\overline{8}$ & 20.0 & -- \\
\hline SPEX-25 & 26.0 & 3.4 & 9 & 25.0 & -- \\
\hline SRWS 93 & 21.5 & 1.7 & 38 & 19.4 & 4.1 \\
\hline SRWS 101 & 50.7 & 4.8 & 38 & 50.0 & 5.5 \\
\hline SRWS 103 & 37.2 & 4.0 & 28 & 36.5 & 4.9 \\
\hline SRWS 105 & 22.6 & 2.8 & 27 & 22.5 & 4.3 \\
\hline SRWS 107 & 16.7 & 2.1 & 27 & 15.0 & 3.9 \\
\hline SRWS 111 & 12.4 & 2.9 & 38 & 14.0 & 3.9 \\
\hline SRWS 113 & 31.1 & 4.1 & 28 & 34.0 & 4.8 \\
\hline SRWS 115 & 47.0 & 4.8 & 21 & 46.0 & 5.4 \\
\hline SRWS 117 & 12.5 & .6 & 10 & 11.8 & 2.0 \\
\hline SRWS 119 & 11.2 & .7 & 28 & 11.9 & 2.5 \\
\hline SRWS 123 & 8.9 & .5 & 10 & 9.2 & 2.4 \\
\hline SRWS 125 & 19.3 & .8 & 28 & 20.1 & 3.0 \\
\hline
\end{tabular}

${ }^{1}$ Standard deviation established from interlaboratory study by the Branch of Technical Development and Quality Systems. 
In addition, the precision and accuracy of GF-AAS and F-AAS methods are compared using SRWS 119, 123, and 125 in figure 7. The results of the GF-AAS and the F-AAS analyses are shown as well as the theoretical most probable values and standard deviations for the SRWS. The accuracy of GF-AAS and F-AAS metheds is comparable; however, GF-AAS shows slightly better precision than F-AAS.

A comparison of methods using water samples further demonstrates acc iracy between the GF-AAS and F-AAS methods. A total of 179 water samples was analyzed for molybdenum by each method (see figs. 8 and 9). A sign test was used to determine whether the median of differences between the two methods differed significantly from zero for samples of both types of water.

The sign test for 108 filtered water samples analyzed by both techniques yielded a $p$-value equal to 0.0003 , indicating that at a high level of probability, tho median of differences is not equal to zero. However, the analytical significance of the median difference of $-0.1 \mu \mathrm{g} / \mathrm{L}$, and an average of $-0.3 \pm 1.0 \mu \mathrm{g} / \mathrm{L}$, is negligible, since it is well below the method reporting limit. In fact, 50 percent of the differences fell between -0.7 and $0 \mu \mathrm{g} / \mathrm{L}$. Therefore, in terms of analytical accuracy from the dissolved analysis results of over 100 filtered water samples, GF-AAS and F-AAS are analytically equivalent.

The sign test on the differences between the same methods for 71 nonfiltered water samples by WWR analysis yielded a $p$-value equal to 0.0000 , demonstrating that the median of the differences for GF-AAS and F-AAS WWR analysis results is significantly different from zero at the 95th percent confidence level. However, as with the dissolved results, the median difference of $0 \mu \mathrm{g} / \mathrm{L}$ for WWR analysis is not analytically significant, since the mean was $-0.9 \pm 1.5 \mu \mathrm{g} / \mathrm{L}$, and 50 percent of the differences fell between -1.3 and $0 \mu \mathrm{g} / \mathrm{L}$.

In contrast to the dissolved analysis, the precision of the WWR molybdenum in nonfiltered samples was slightly more variable, as shown in figure 9. Becauso of the larger variation demonstrated with WWR analysis sample comparison, some Standard Reference Water Samples were analyzed by WWR analysis and charted against their known means and deviations. The results listed in table 6 confirm the accuracy of the GF-AAS method for WWR matrices.

Table 6.--Precision and accuracy results for whole water recoverable Standard Reference Water Samples relative to their theoretical means and deviations

[GF-AAS, graphite furnace atomic absorption spectrophotometry; $n$, number of determinations; WWR, whole water recoverable; SRWS, Standard Reference IVater Sample. All measurements in micrograms per liter]

\begin{tabular}{|c|c|c|c|c|c|}
\hline \multirow[b]{2}{*}{$\begin{array}{l}\text { Reference } \\
\text { number }\end{array}$} & \multicolumn{2}{|c|}{ GF-AAS } & & \multicolumn{2}{|c|}{ Theoretical } \\
\hline & Mean & $\begin{array}{l}\text { Standard } \\
\text { deviation }\end{array}$ & $\mathrm{n}$ & Mean & $\begin{array}{l}\text { Standard } \\
\text { deviation }\end{array}$ \\
\hline WWR SRWS 119 & 11.6 & 0.5 & 8 & 11.9 & 2.5 \\
\hline WWR SRWS 121 & 12.0 & .5 & 9 & 12.0 & 2.5 \\
\hline WWR SRWS 123 & 8.9 & .4 & 10 & 9.2 & 2.4 \\
\hline WWR SRWS 125 & 19.6 & .8 & 10 & 20.1 & 3.0 \\
\hline
\end{tabular}




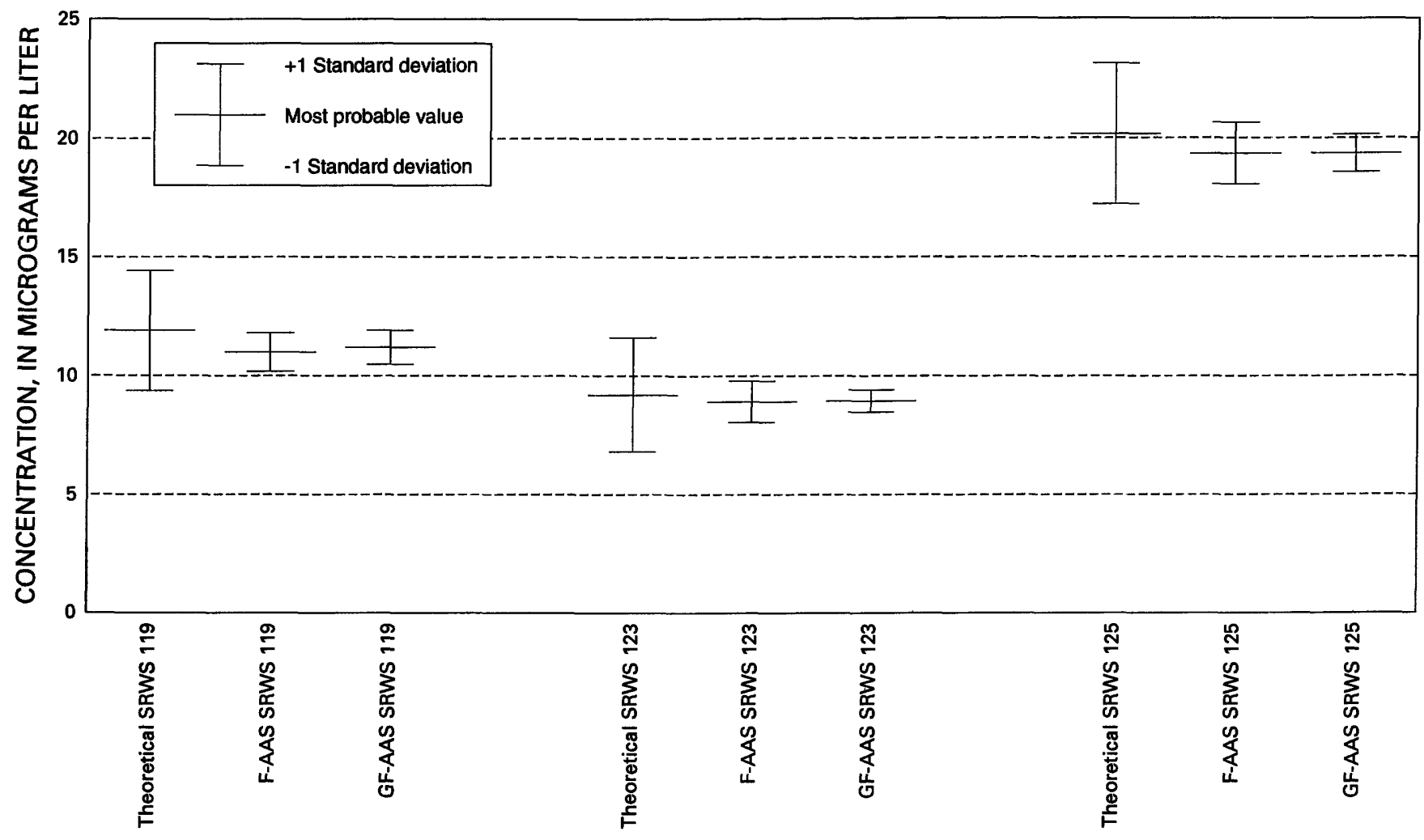

\section{EXPLANATION}

[All concentrations in micrograms per liter; $n=$ number of determinations; F-AAS, flame atomic absorption spectrophotometry; GF-AAS, graphite furnace atomic absorption spectrophotometry; SRWS, Standard Reference Water Sample; n/a, not applicable]

\begin{tabular}{|c|c|c|c|c|c|c|c|c|c|c|c|c|}
\hline & \multicolumn{4}{|c|}{ Theoretical } & \multicolumn{4}{|c|}{ F-AAS } & \multicolumn{4}{|c|}{ GF-AAS } \\
\hline & Mean & & Deviation & $\mathrm{n}$ & Mean & & Deviation & $\mathbf{n}$ & Mean & & Deviation & $\mathrm{n}$ \\
\hline SRWS 119 & 11.9 & + & 2.5 & $\mathrm{n} / \mathrm{a}$ & 11.0 & + & 0.8 & 28 & 11.2 & + & 0.7 & 28 \\
\hline SRWS 123 & 9.2 & + & 2.4 & $\mathrm{n} / \mathrm{a}$ & 8.9 & + & 0.9 & 10 & 8.9 & + & 0.5 & 10 \\
\hline SRWS 125 & 20.1 & + & 3.0 & $\mathrm{n} / \mathrm{a}$ & 19.3 & + & 1.3 & 28 & 19.3 & + & 0.8 & 28 \\
\hline
\end{tabular}

Figure 7.--Precision and accuracy results for molybdenum determination by flame and graphite furnace atomic absorption spectrophotometry relative to Standard Reference Water Samples. 


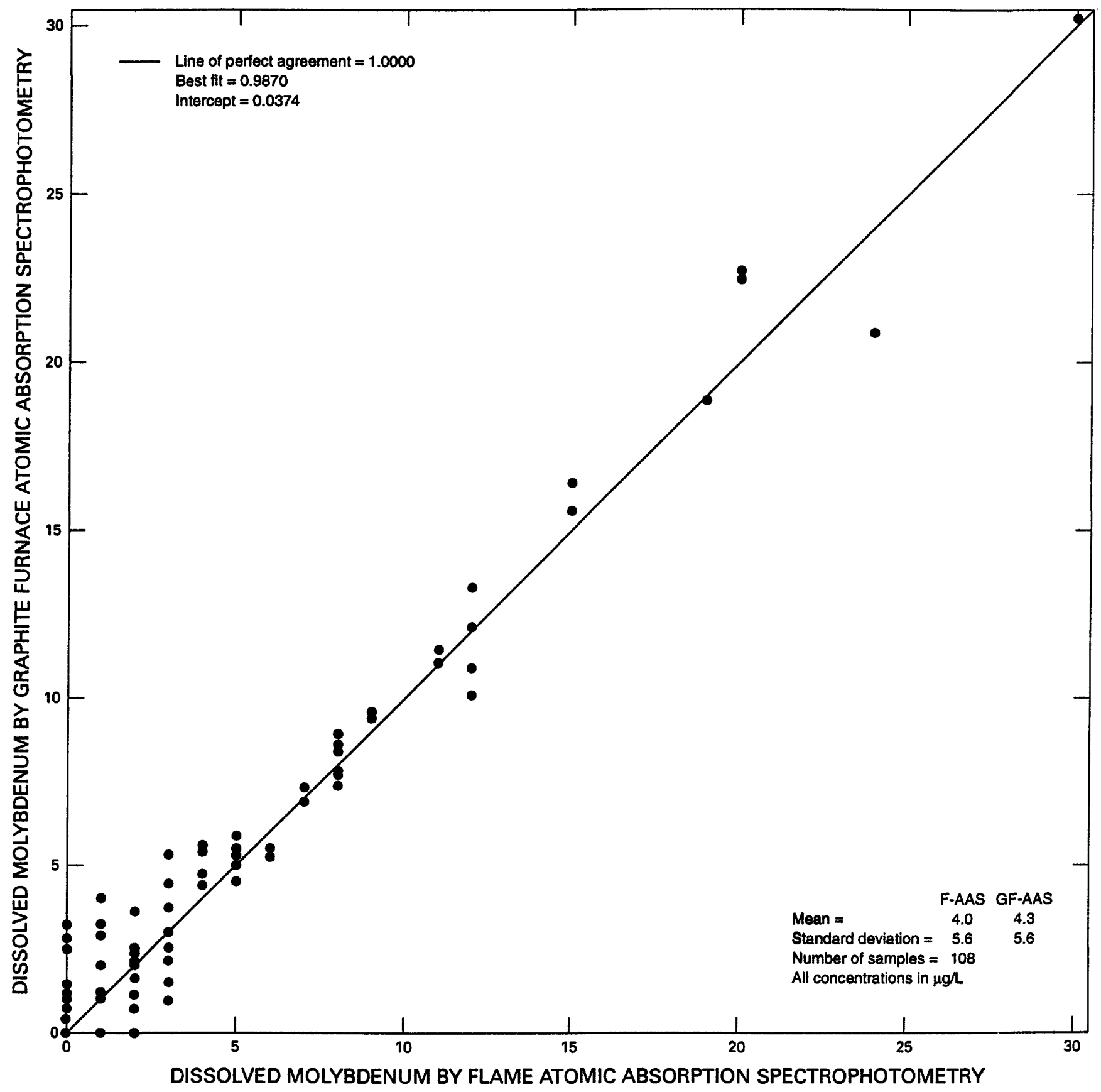

Figure 8.--Results for the determination of dissolved molybdenum in filtered water samples analyzed by graphite furnace atomic absorption spectrophotometry (GF-AAS) relative to flame atomic absorption spectrophotometry (F-AAS). 


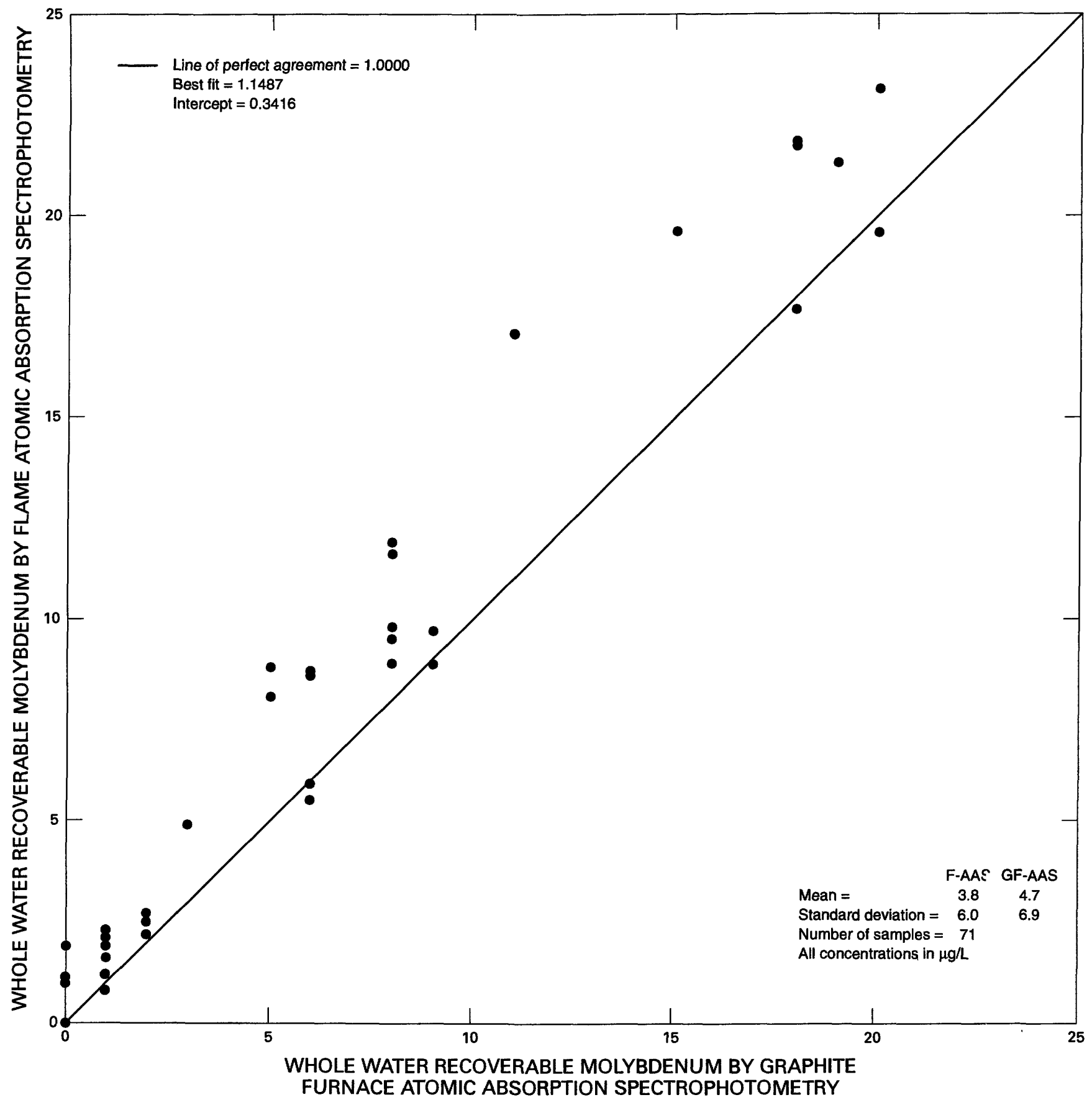

Figure 9.--Results for the determination of whole water recoverable molybdenum in nonfiltered water samples analyzed by graphite furnace atomic absorption spectrophotometry (GF-AAS) relative to flame atomic absorption spectrophotometry (F-AAS). 
Twenty-six filtered water samples were analyzed by the ICP-MS and GF-AAS methods to further verify accuracy of the GF-AAS method (see fig. 10). Results from both methods were compared by calculating the differences between method results. Since the differences were found to be normally distributed, the paire $t$-test (Ott, 1993, p. 293) was used to determine whether the mean of the differences between the two methods differed significantly from zero. The $t$-test on the differences for 26 samples analyzed by each method yielded a $p$-value equal to 0.025 . Therefore, the mean of the differences between ICP-MS and GF-AAS is statistically different from zero at the 95th percent confidence level; however, the mean cf the differences was $0.1 \pm 0.3 \mu \mathrm{g} / \mathrm{L}$, a concentration well below the method reporting limit for both methods.

\section{QUALITY ASSURANCE}

Minimum quality-control requirements include analysis of laboratory reagent blanks and quality-control samples, which must include SRWS and may include intermediate check standards, sample duplicates, and sample spikes. All WWR sets include a digested SRWS and reagent blank to verify sample integrity during the digestion process. Field spikes are encouraged as an additional che $\% k$. Refer to Pritt and Raese (1995) for further definition of NWQL's goals and incrganic requirements.

\section{CONCLUSION}

The GF-AAS method is an efficient and effective technique for the determination of molybdenum at trace-concentration levels. It offers a low detection limit and precise and accurate data without the use of hazardous organic materials. The small sample size, absence of sample preparation, and minimal interference problems make it an attractive analytical tool for determining molybdenum in various types of water samples. 


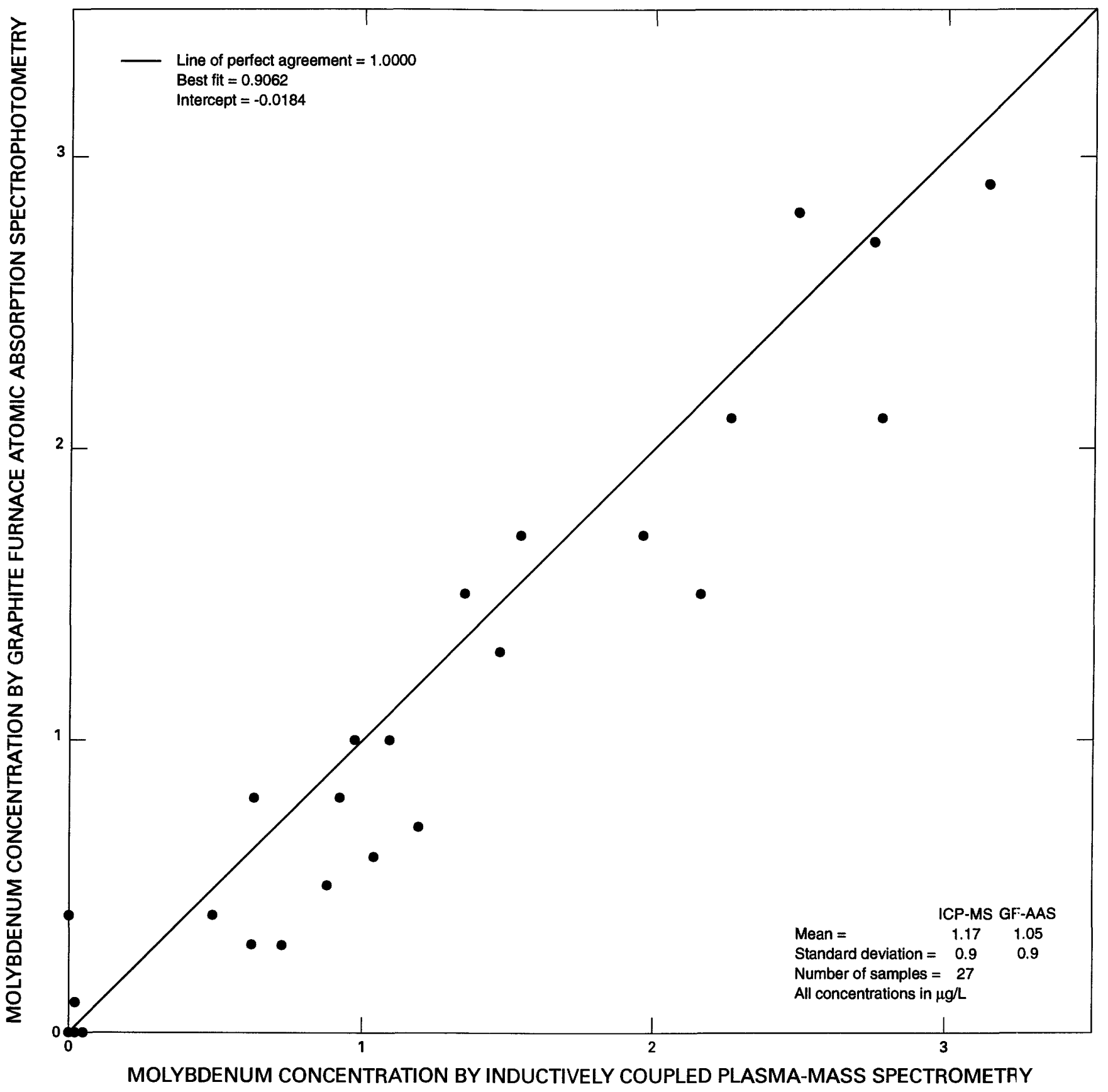

Figure 10.--Results for the determination of dissolved molybdenum in filtered water samples analyzed by graphite furnace atomic absorption spectrophotometry (GF-AAS) relative to inductively coupled plasma-mass spectrometry (ICP-MS). 


\section{REFERENCES CITED}

American Society for Testing and Materials, 1995, Annual book of ASTM standards, Section II, Water: Philadelphia, v. 11.01, p. 122-124.

Beaty, R.D., 1988, Concepts, instrumentation and techniques in atomic absorption spectrophotometry: Perkin-Elmer Corp., chaps. 5 and 6, variable pagination.

Beaty, R.D., and Kerber, J.D., 1993, Concepts, instrumentation and techniques in atomic absorption spectrophotometry: Perkin-Elmer Corp., chaps. 5 and 6.

Emerick, R.J., 1987, Calcium chloride matrix modification for preventing sulfate interference in the determination of molybdenum by graphite furnace atomic absorption spectrophotometry: Atomic Spectroscopy, v. 8, no. 2, p. 69--71.

Fishman, M.J., 1993, Methods of analysis by the U.S. Geological Survey National Water Quality Laboratory--Determination of inorganic and organic constituents in water and fluvial sediments: U.S. Geological Survey OpenFile Report 93-125, 217 p.

Fishman, M.J., and Friedman, L.C., 1989, Methods for determination of inorganic substances in water and fluvial sediments: U.S. Geological Survey Techniques of Water-Resources Investigations, book 5, chap. A1, 545 p.

Ghe, A.M., Carati, Daniela, and Stefanelli, Claudio, 1983, Determination of trace amounts of molybdenum by flame and flameless atomic absorption spectrometry: Annali di Chimica, p. 711.

Hem, J.D., 1989, Study and interpretation of the chemical characteristics of natural water: U.S. Geological Survey Water-Supply Paper 2254, 3rd ed., p. 140.

Hoffman, G.L., Fishman, M.J., and Garbarino, J.R., 1996, Methods of analysis by the U.S. Geological Survey National Water Quality Laboratory--In-bottle acid digestion of whole-water samples: U.S. Geological Survey Open-File Report 96-225, $28 \mathrm{p}$.

Ott, R. L., 1993, An introduction to statistical methods and data analysis: Durbury Press, 4th edition, p. 293 and 297-301. 
Pritt, J.W., and Raese, J.W., 1995, Quality assurance/quality control manual-National Water Quality Laboratory: U.S. Geological Survey Open-File Report 95-443, $35 \mathrm{p}$.

Slavin, W., 1984, Graphite furnace AAS: Perkin-Elmer Corp., p. 123.

U.S. Environmental Protection Agency, 1993, Primary drinking-water regulations, maximum contaminant levels (Appendix B to part 136, National primar'r drinking-water regulations): U.S. Code of Federal Regulations, Title 40, Farts 100-149, revised as of July 1, 1993, p. 569-570. 